\title{
RECURSOS TECNOLÓGICOS POTENCIALIZADORES DO ENSINO NÃO PRESENCIAL EM TEMPOS DE PANDEMIA DA COVID-19
}

\section{TECHNOLOGICAL RESOURCES THAT ENHANCE NON-FACE-TO-FACE EDUCATION IN TIMES OF THE COVID-19 PANDEMIC}

Bianca Rodrigues de Oliveira Discente em Biblioteconomia e Documentação do Instituto de Ciência da Informação (ICI)

Universidade Federal da Bahia (UFBA)

Talita Karen Santos Barros Discente do Bacharelado Interdisciplinar em Humanidades Universidade Federal da Bahia (UFBA)

Kátia Oliveira Rodrigues Professora do Instituto de Ciência da Informação (ICI) Universidade Federal da Bahia (UFBA)

Jaires Oliveira Santos Professora do Instituto de Ciência da Informação (ICI) Universidade Federal da Bahia (UFBA)

Taise Oliveira Santos Graduada em Biblioteconomia e Documentação pelo Instituto de Ciência da Informação (ICI) Universidade Federal da Bahia (UFBA)

Submetido em: $31 / 07 / 2020$

Aceito em: 05/10/2020

Publicado em: 12/10/2020

Licença:

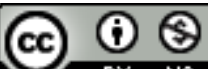

Autor para correspondência: Bianca Rodrigues de Oliveira E-mail: bianca75300@gmail.com/biancaro@ufba.br ORCID: https://orcid.org/0000-0001-9798-6504

\section{Como citar este artigo:}

OLIVEIRA, Bianca Rodrigues et al. Recursos tecnológicos potencializadores do ensino não presencial em tempos de pandemia da COVID-19. REBECIN, São Paulo, v. 7, número especial, p. 129-155, 2020. DOI: 10.24208/rebecin.v7iespecial.204 


\title{
RESUMO
}

O surgimento da Pandemia do novo coronavírus ocorreu de maneira repentina e surpreendeu a todos com o fechamento de fronteiras, atividades comerciais e encerramento generalizado de todas as atividades nas instituições de ensino por tempo indeterminado. Este cenário evidencia a necessidade emergente da inserção de ferramentas tecnológicas na educação de forma mais efetiva, de modo que o ensino seja assegurado e a interação entre professores e alunos possa ser efetiva. Assim, o presente artigo reflete a educação não presencial implantada de modo compulsório e identifica recursos tecnológicos que podem viabilizar o acesso informacional e a interação entre alunos, professores e tutores no contexto educacional de pandemia. Para atender a esta pretensão, empreendeu-se uma pesquisa bibliográfica e documental. Constatou-se que as atividades não presenciais podem ser potencializadas com o uso de recursos estratégicos das tecnologias da informação e comunicação (TIC), a fim de garantir o diálogo entre os sujeitos da educação e o acesso efetivo a recursos informacionais, indispensáveis ao decurso de aprendizagem. Por outro lado, essa transposição excepcional pode contribuir para o acirramento das desigualdades sociais, principalmente daquelas pessoas que já estão em situação de vulnerabilidade social.

Palavras-Chave: Tecnologias educacionais e informacionais. Covid-19. Ferramentas educacionais digitais. Educação não presencial. Educação remota.

\begin{abstract}
The emergence of the Pandemic of the new coronavirus occurred suddenly and surprised everyone with the closure of borders, commercial activities and widespread closure of all activities in educational institutions indefinitely. This scenario highlights the emerging need for the insertion of technological tools in education more effectively, so that teaching is ensured and the interaction between teachers and students can be effective. Thus, this article reflects the non-face-to-face education implemented in a compulsory way and identifies technological resources that can enable informational access and interaction between students, teachers and tutors in the educational context of pandemia. To meet this claim, a bibliographic and documentary research was undertakenl. It was found that nonface-to-face activities can be enhanced with the use of strategic resources of Information and Communication Technologies (ICT), in order to ensure dialogue between the subjects of education and effective access to information resources, indispensable for the course of learning. On the other hand, this exceptional transposition can contribute to the increasing extent of social inequalities, especially those people who are already in a situation of social vulnerability.
\end{abstract}

Keywords: Educational and informational technologies. Covid-19. Digital educational tools. Non-face-to-face education. Remote education.

\section{INTRODUÇÃO}

A informação está no cotidiano pessoal e profissional dos sujeitos durante o curso de sua vida. No caso específico dos estudantes, admite-se que eles usam e 
acessam constantemente informações para desenvolver as suas tarefas educacionais, logo, a informação está inclusa no seu processo de aprendizagem. Em um cenário de grande proliferação de informações e desinformações, os sujeitos precisam desenvolver competências para identificá-las e discerni-las, de modo a eleger aquela que efetivamente contribua para a construção de seus saberes.

Atualmente, a pandemia da COVID-19 (SARS-CoV-2) faz o mundo (re)pensar estratégias para conviver com os efeitos devastadores da doença do ponto de vista sanitário, do isolamento social, da infodemia e da concepção de estrutura e execução de aulas não presenciais. A adaptação das atividades educacionais para essa modalidade tem sido amplamente discutida e implementada no contexto nacional e mundial, em vista da conjuntura pandêmica.

No Brasil, ganham destaque algumas questões acerca desta reorganização das atividades educacionais, especialmente com a divulgação das Portarias do Ministério da Educação (MEC) de $n^{\circ}$ 343, de 17 de março de 2020 (BRASIL, 2020a) e 345, de 19 de março de 2020 (BRASIL, 2020b) - que constituiu o primeiro marco regulatório para a substituição das disciplinas presenciais por aulas que façam uso das TIC. A Portaria de no 544, de 16 de junho de 2020 substituiu as supracitadas e "dispõe sobre a substituição das aulas presenciais por aulas em meios digitais enquanto durar a situação de pandemia do Novo Coronavírus - COVID-19." (BRASIL, 2020d, p. 62) com validade até 31 de dezembro de 2020.

Em vista dessa conjuntura, esse artigo reflete a educação não presencial implantada de modo compulsório e identifica recursos tecnológicos que podem viabilizar o acesso informacional e a interação entre alunos, professores e tutores no contexto da educação em tempos de pandemia.

\section{BREVE HISTORICIDADE DA EDUCAÇÃO A DISTÂNCIA}

Os primórdios da Educação a Distância (EaD) revelam práticas semelhantes ao que estamos vivenciando com esse momento pandêmico, guardadas as proporções das condições tecnológicas de cada período histórico. Embora existam registros de EaD anterior ao século XVIII, Alves (2011) sinaliza como marco inicial da EaD o envio de tutoria por correspondências para os estudantes de um curso 
divulgado pela Gazeta de Boston em 1728. O autor também sinaliza o emprego de outras tecnologias para a educação na modalidade a distância como o rádio em 1935 no Japão, em 1956 a televisão assume o protagonismo na transmissão da informação educacional. É importante esclarecer que esta modalidade de ensino era utilizada principalmente para formação técnica e complementação do ensino presencial, anos mais tarde, passou a ser utilizada também por alunos que viviam afastados dos centros de ensino.

No Brasil, a institucionalização da EaD ocorreu por volta de 1904, também nessa mesma perspectiva, onde ofereceu-se cursos, por correspondência, divulgados por intermédio de anúncios em jornais, seguido do rádio, televisão, até mais recentemente com o uso amplamente difundido das Tecnologias da Informação e Comunicação (TIC) (ALVES, 2011), como serão detalhados a seguir. Já na década de 1920, o Brasil foi marcado por grandes reformas educacionais, onde destacaramse Anísio Teixeira, Fernanda de Azevedo e Manuel Lourenço Filho.

$\mathrm{Na}$ década de 1960, os meios de telecomunicações, mais precisamente o rádio, foram utilizados como forma de disseminar as informações para um grande número de pessoas simultaneamente. A Lei $n^{\circ} 4.117$, de 27 de agosto de 1962, que institui o Código Brasileiro de Telecomunicações, em seu art. 38 afirma que "[...] d) os serviços de informação, divertimento, propaganda e publicidade das empresas (sic) de radiodifusão estão subordinadas às finalidades educativas e culturais inerentes à radiodifusão, visando aos superiores interesses do País." (BRASIL, 1962, p. 10413). A Rádio Sociedade foi uma das empresas de radiodifusão que oferecia atividades com finalidades educativas e culturais, a exemplo das aulas de português, francês, geografia, história, entre outras disciplinas. Para Barros ([20--], p. 2),

os processos de ensino e aprendizagem, enfocados na radiodifusão, abrem perspectivas para a construção de novos paradigmas que perpassam pelas questões educacionais, midiáticas, [informacionais], culturais e cotidianas que viabilizem o melhor entendimento e amplitude da cidadania.

Assim como o rádio, outras iniciativas foram fomentadas pelo governo, tendo a televisão como tecnologia, a exemplo dos canais da TV Escola e TV Cultura, com uma programação voltada para temáticas educacionais, que mais tarde 
consolidaram suas programações atreladas às práticas científicas e culturais. No ano de 1978, a Fundação Roberto Marinho em parceria com a Federação das Indústrias do Estado de São Paulo (Fiesp), criaram o "Telecurso", que objetivava "[...] ampliar o acesso à educação a centenas de milhares de brasileiros, ao levar educação de qualidade pela TV, com uma linguagem, formato e modelo de atuação inovadores." (FUNDAÇÃO ROBERTO MARINHO, 2019).

A referida iniciativa beneficiou mais 1,6 milhões de estudantes em todo território nacional. A metodologia utilizada para o sucesso do programa consistiu em uma formação continuada para professoras e professores com acompanhamento pedagógico junto à avaliação de atividades (FUNDAÇÃO ROBERTO MARINHO, 2019). Apesar dessas iniciativas, a EaD no Brasil, como política pública só se efetivou a partir do Decreto $n^{\circ}$ 9. 057, de 25 de maio de 2017, que regulamentou 0 art. 80 da Lei de Diretrizes Básicas de Educação (LDB), considerando a EaD como:

[...] a modalidade educacional na qual a mediação didático-pedagógica nos processos de ensino e aprendizagem ocorra com a utilização de meios e tecnologias de informação e comunicação, com pessoal qualificado, com políticas de acesso, com acompanhamento e avaliação compatíveis (sic), entre outros, e desenvolva atividades educativas por estudantes e profissionais da educação que estejam em lugares e tempos diversos (BRASIL, 2017, p. 3).

Desde então, observa-se uma mudança significativa no cenário da EaD no Brasil pois, com a aprovação do decreto, apesar dos procedimentos legais a serem instituídos nesta modalidade de ensino, o decreto favorece o crescimento do número de instituições que aderem à essa modalidade de ensino. Na concepção de Alves (2011), a EaD é uma maneira estruturada de auto estudo, onde os estudantes acessam materiais de estudo, a partir de plataformas digitais e contam com o acompanhamento de uma equipe de professores.

Com o avanço das TIC foi possível a inclusão de diferentes ferramentas nas metodologias de ensino e aprendizagem, com a finalidade de articular a interação professor-aluno. Moore e Kearsley (2013) expõem a história do EaD dividida em 5 gerações que transita por diferentes tecnologias, do suporte informacional papel ao digital (Quadro 1): 
Quadro 1 - Gerações da EaD

\begin{tabular}{|c|l|}
\hline 10 Geração & $\begin{array}{l}\text { Marcada pela comunicação textual, por meio de } \\
\text { correspondência. }\end{array}$ \\
\hline 2 Geração & Ensino por rádio e televisão. \\
\hline $3^{\circ}$ Geração & $\begin{array}{l}\text { Caracterizada, principalmente, pela invenção das } \\
\text { universidades abertas. }\end{array}$ \\
\hline 4 Geração & $\begin{array}{l}\text { Distinta pela interação à distância em tempo real, } \\
\text { em cursos de áudio evideoconferências. }\end{array}$ \\
\hline 50 Geração & $\begin{array}{l}\text { Envolve o ensino e o aprendizado on-line, em } \\
\text { classes e universidades virtuais, baseadas em } \\
\text { tecnologias da internet. }\end{array}$ \\
\hline
\end{tabular}

Fonte: adaptado de Moore e Kearsley (2013).

Embora coadunemos com a ideia de que a EaD, enquanto política pública, difere muito da aplicabilidade das atividades não presenciais/remotas, admitimos que $\mathrm{o}$ uso de algumas estratégias consolidadas na modalidade EaD ajudam no aprimoramento das práticas estabelecidas de modo compulsório no período pandêmico. Nessa conjuntura, torna-se relevante apresentar ações desejáveis de interação entre os sujeitos da educação para que seja levado a cabo um decurso de ensino e aprendizagem de modo eficaz.

\subsection{PRÁTICAS DE INTERAÇÃO PROFESSOR, ALUNO E TUTOR NA EAD APLICÁVEIS NO CONTEXTO DA PANDEMIA DA COVID-19}

No processo de ensino e aprendizagem, a interação professor-aluno desempenha papel fundamental, em especial na modalidade a distância. Nessa perspectiva, Vendruscolo e Behar (2016) relatam que o modelo de ensino a distância exige maior responsabilidade do aluno com seu aprendizado, assim como organização, disciplina e autonomia. Em contrapartida, os professores e tutores - 
presencial e a distância -, devem exercer o papel de mediadores do processo de ensino e aprendizagem, incentivando o interesse dos alunos através de diferentes estratégias. No caso específico dos tutores, é relevante frisar que ambos (presenciais e a distância) são capacitados nos conteúdos das disciplinas e na metodologia de educação a distância, com vistas ao acompanhamento dos alunos em disciplinas teóricas e/ou práticas.

Existem três faces da interação que influenciam diretamente no desempenho da aprendizagem. São elas: 1) a ação inicial do professor; 2) a relação aluno-aluno; 3) a relação final aluno-professor (FREIRE, 2000). Assim na primeira abordagem elencaríamos a didática, que está envolta no processo de formação do profissional, além da transmissão de informação, em consonância com a realidade de seu/sua aluno(a). A segunda como processo de socialização e interação do ser humano, ligados à sua necessidade de aprendizado. A terceira refere-se ao decurso de apropriação da informação, transformando-as em conhecimento.

Sobre os processos interativos na EaD observa-se que as instituições de ensino foram aperfeiçoando ao longo do tempo e disponibilizando novos recursos para os alunos, como: plantões de dúvidas, fóruns de discussão para troca de ideias, bibliotecas virtuais, dentre outros. Ao optarem por realizar uma formação na modalidade $\mathrm{EaD}$, os alunos devem ter suporte de acesso à informação para suprir as necessidades básicas no seu desenvolvimento acadêmico. Contudo, é oportuno sinalizar que as instituições que ofertam cursos $\mathrm{EaD}$, além de seguir normas específicas na elaboração e disseminação dos conteúdos educacionais, devem também gerenciar, aspectos como design, ergonomia, acessibilidade, para que a interface do software seja passiva da interação humana. Outro aspecto que se deve observar na EaD quando se discute a questão da interação é a personalização do layout de apresentação da página do software, para torná-la mais atrativa.

Assim como as questões técnicas, a mediação da informação feita pelo professor, nesta modalidade de ensino, ocorre a partir da facilidade aos pontos de acesso à informação: primária, que seria basicamente o material produzido pelo próprio professor, entre eles videoaulas, podcasts, animações entre outros; secundária, onde estariam os materiais complementares como livros, capítulo de 
livros em PDF ou Epub e a terciária, como uma intermediária a novas informações, como catálogos, revisão de literatura etc. (CAMPELO; CENDÓN; KREMER, 2007).

De acordo com os parâmetros do MEC, a forma com que os professores, alunos e coordenadores se comunicam quer dizer muito sobre a qualidade do ensino que a instituição está ofertando. Esse processo de comunicação e interação com as mais diversas ferramentas é de extrema relevância para formação do aluno. Essa dinâmica proporciona de acordo com Meirinhos e Osório (2014, p. 64-65):

uma nova cultura colaborativa, a qual poderá, no contexto atual, desenvolver-se cada vez mais e apreender (sic), progressivamente, o potencial educativo das redes, potenciar a inovação e traduzi-la em efeitos educativos concretos, renovando os sistemas educativos e de formação.

Isto posto, percebe-se que para obter maior êxito no processo de aprendizagem virtual, a interação e a interface são os indicadores de qualidade mais eficazes e as instituições devem ofertar projetos pedagógicos que priorize essa interação mútua em seus ambientes virtuais de aprendizagem. Ademais, as relações entre professor e aluno demonstram ser de suma importância na construção de um saber coletivo e na quebra de paradigmas pedagógicos na utilização dos sistemas virtuais de aprendizagem. É inevitável constatar, portanto, que nesse contexto de pandemia, essa interação é de vital importância e o uso de recursos tecnológicos e informacionais se constitui em um diferencial para lograr êxito nessa dinâmica.

\section{EDUCAÇÃO NÃO PRESENCIAL EM TEMPOS DE COVID-19}

A sociedade está vivenciando um cenário único com a pandemia do Novo Coronavírus, doença respiratória grave, que foi registrada pela primeira vez em Wuhan, na China, e que registrou inúmeros casos desde a internação do primeiro paciente (FAN et al., 2020). No Brasil, o primeiro caso confirmado de Coronavírus ocorreu no dia 26 de fevereiro de 2020, de um paciente internado no Hospital Albert Einstein, do sexo masculino, 61 anos, que havia viajado para a Itália (LINHA..., 2020). Desde então, diversos setores da sociedade tiveram suas atividades presenciais interrompidas. 
$\mathrm{Na}$ educação, o grande marco na regulamentação deste modo deu-se no dia 17 de março de 2020, momento em que o MEC assinou a Portaria no 343 que autoriza a substituição das aulas presenciais por aulas que usem os recursos das tecnologias digitais por um período de 30 dias prorrogáveis enquanto durar a pandemia do Novo Coronavírus. Em 19 de março de 2020, o Ministério publica a Portaria de no 345 e ela altera o texto do artigo primeiro da Portaria anterior ( $\left.n^{\circ} 343\right)$. Então, por meio deste documento, o MEC resolve que:

art. 1 fica autorizada, em caráter excepcional, a substituição das disciplinas presenciais, em andamento, por aulas que utilizem meios e tecnologias de informação e comunicação, por instituição de educação superior integrante do sistema federal de ensino, de que trata o art. $2^{\circ}$ do Decreto $n^{0} 9.235$, de 15 de dezembro de 2017. (BRASIL, 2020b, p. 1).

É oportuno esclarecer que a portaria não substitui a educação na modalidade presencial em modalidade a distância, apenas o uso de tecnologias de informação e comunicação para as aulas em virtude do cenário sanitário. De acordo com a portaria, cabe às instituições de ensino "[...] comunicar ao Ministério da Educação tal providência [do emprego das tecnologias para ministrar as disciplinas] no período de até quinze dias [...]" (BRASIL, 2020a, p. 39), além de ter a responsabilidade de definir as disciplinas que poderão ser substituídas e ofertar ferramentas aos alunos para o desenvolvimento das atividades à distância. Em 12 de maio de 2020, a Portaria no 473 prorrogou, por mais trinta dias, a partir do dia 15 de maio a determinação da Portaria no 343 e suas respectivas alterações previstas na Portaria $n^{\circ} 345$.

Contudo, em 16 de junho de 2020, foi publicada a Portaria de $n^{0} 544$, que revogou e substituiu as anteriores que versam sobre essa questão educacional nesse contexto pandêmico. Nela, o MEC traz alguns esclarecimentos gerais sobre o modus operandi desse ensino e determina que a autorização se estenda até o fim de 2020. No artigo primeiro, por exemplo, fez mudanças importantes para a tomada de decisão das instituições de ensino, que puderam pensar em oferecer cursos que não estavam em andamento, já que não consta esse grifo no texto atual.

Diante desse cenário hodierno, as instituições de ensino, professores, alunos, pais e responsáveis, tiveram que se adaptar às ferramentas tecnológicas de comunicação e informação como medida de enfrentamento à pandemia. E a 
educação que em sua grande maioria tinha seus materiais vinculados aos suportes físicos, como por exemplo, livros didáticos, apostilas, folhetos, revistas entre outros, passou a ter as mídias e recursos tecnológicos, como um dos fatores primordiais na realização das atividades.

Com as mídias e documentos em formato digital, a organização de tais recursos educacionais também precisou se transformar, sendo necessária a criação de espaços digitais, ferramentas de apoio ao design de interface. Logo, manter a atenção do aluno através da tela das TIC, requer ainda mais habilidades do professor, como mediador da informação em prol da formação e do conhecimento.

Ainda sobre a adaptação às tecnologias do ensino durante a pandemia, a Organização das Nações Unidas para a Educação, a Ciência e Cultura (Unesco) aponta que mais de $80 \%$ dos alunos no mundo já tiveram suas atividades escolares/acadêmicas afetadas por conta das regras de distanciamento social adotadas pelas autoridades de saúde. Embora as aulas em meio digital tenham sido implementadas em caráter emergencial em parte das instituições de ensino, na tentativa de minimizar os danos causados pela ausência das atividades escolares/acadêmicas presenciais, esta substituição acende um alerta sobre o acesso à educação dos sujeitos menos favorecidos economicamente. Isso porque essa medida pode aumentar as desigualdades sociais, já que é preciso ter o equipamento tecnológico e o acesso à internet de qualidade mediana para que seja possível o contato do aluno com os materiais informacionais das aulas e a interação com o professor/tutor. Ademais, é necessário que os estudantes tenham o domínio das plataformas digitais para acompanhar os conteúdos propostos.

Sobre o acesso à internet no Brasil, salienta-se que "[...] 67\% dos domicílios possuem acesso à rede, sendo esse percentual muito diferente entre classes sociais: $99 \%$ para aqueles da classe $A, 94 \%$ na $B, 76 \%$ na $C$ e $40 \%$ na D e E." (TODOS PELA EDUCAÇÃO, 2020, p. 9). Assim, torna-se urgente que o Estado atue efetivamente na criação de medidas que culminem na construção de um plano político pedagógico emergencial, a fim de garantir os direitos dos menos favorecidos e que eles consigam ter acesso à informação e educação de modo digno.

\section{FERRAMENTAS DE INTERAÇÃO/COMUNICAÇÃO E ORGANIZAÇÃO DE INFORMAÇÕES EDUCACIONAIS NOS AMBIENTES DIGITAIS}


A educação com auxílio das tecnologias de informação e comunicação pressupõe uma forte estrutura de apoio e acompanhamento ao aluno em sua trajetória formativa. Dado o contexto atual, Maia e Silva (2020) explicitam os esforços na inserção de ferramentas que auxiliem e viabilize as práticas educativas, como as atividades sincrônicas (webconferências, videoconferências e chats) e assincrônicas (como fórum, correio eletrônico) realizadas em ambientes virtuais de aprendizagem que auxiliam a inserção de novas formas de interação social e novos modelos de aprendizagem.

Os autores trazem também uma reflexão que trata da "modalidade" e "nomenclatura" do ensino à distância, pois, o essencial é voltar à atenção as práticas e fazer o bom uso das TIC à disposição. Portanto a interação/comunicação entre alunos, professores e tutores é fundamental para estimular a autonomia e pode ser potencializada a partir do uso de ferramentas gratuitas, as quais serão descritas a seguir.

\subsection{AMBIENTE VIRTUAL DE APRENDIZAGEM (AVA)}

O AVA proporciona a interação entre alunos, professores e tutores através de atividades ou recursos. Silva e Figueiredo (2012) dizem que esse recurso pode ser denominado também de salas virtuais e possui grandes potencialidades, por viabilizar o diálogo entre os sujeitos da educação (aluno, professor, tutor) e favorecer a dinamização do processo por meio da disponibilização de recursos como videoaulas, exercícios, chats, fóruns, dentre outros.

Um dos ambientes virtuais de aprendizagem mais utilizados é o Modular Object Oriented Dynamic Learning Environment (Moodle). Maia e Silva (2020), ao discutirem acerca das práticas pedagógicas em AVA, também reafirmam sobre a predominância no uso do Moodle como tecnologia no processo de ensino e aprendizagem. A adoção do Moodle em especial nas instituições de ensino superior "[...] se deve às possibilidades que ele agrega no sentido da otimização, integração de módulos e formalização dos processos, e também pela possibilidade de gerenciamento." (MAIA; SILVA, 2020, p. 91). 
O Moodle1 (Figura 1) é um sistema de gestão da aprendizagem que tem como intuito proporcionar aos acadêmicos e professores uma maior dinâmica de ensino dentro e fora da sala de aula. Essa plataforma é utilizada como elemento de suporte às aulas presenciais, ou exclusivamente on-line. O Moodle também funciona como um sistema de administração de atividades educacionais que se destina à criação de comunidades on-line, voltadas para a aprendizagem.

Figura 1 - Tela inicial do Moodle

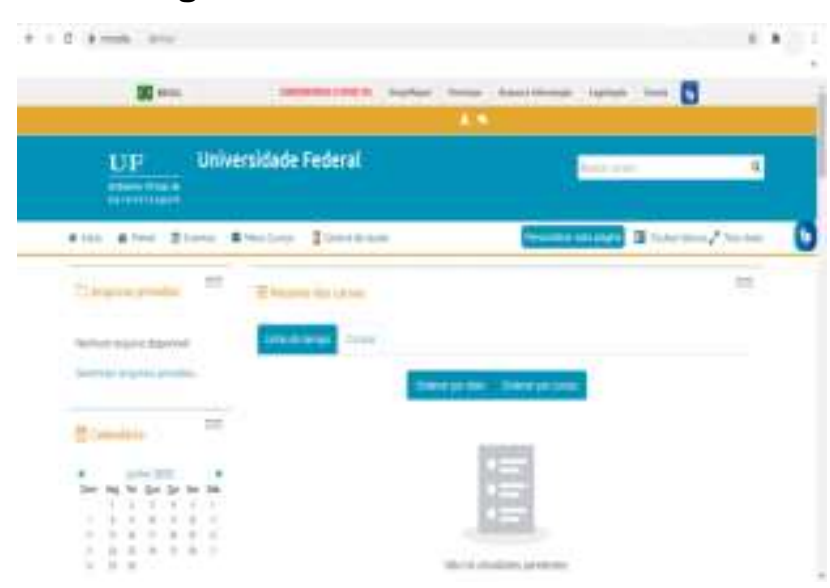

Fonte: captura de tela da ferramenta (2020).

$\mathrm{Na}$ plataforma, a partir das ferramentas da web 2.0, professores, alunos e tutores podem compartilhar materiais de ensino, a exemplo de: apresentações das aulas; trabalhos dos alunos; listas de exercícios e apostilas, criação de fóruns e chats para discussão de diversos assuntos e acesso a sistemas de informação e a bibliotecas digitais.

\subsection{VÍDEO E APRESENTAÇÃO}

Para criação e edição de vídeos temos uma opção, o Animaker. ${ }^{2}$ Este é um software de criação de vídeos animados com cenários, personagens, falas e objetos, ideal para demonstrar situações do dia-a-dia, problema e possíveis resoluções.

\footnotetext{
${ }_{1}^{1}$ Disponível em: https://moodle.org/?lang=pt_br. Acesso em: 14 jul. 2020.

2 Disponível em: https://www.animaker.co. Acesso em: 14 abr. 2020.
} 
Conta com planos pagos, mas também oferece uma versão gratuita, sendo possível a criação de cenários, para contextualizar o objetivo da aula, adicionar músicas ou narração, e ainda modelos prontos com temas usuais que podem ajudar na customização da aula e/ou videoaula.

Outra forma que pode ser empregada para elaboração de vídeos animados para dar um upgrade nas aulas é o PowerPoint. Embora esta ferramenta não apresente a função específica para a elaboração de vídeos animados, é possível a criação de vídeos de altíssima qualidade a partir das abas de animação e transições, conforme a ordem da aula. O PowerPoint pode ser útil, também, quando usado em conjunto com outras ferramentas, a exemplo do Loom ${ }^{3}$ - software de gravação de tela, que permite gravação de áudio e vídeo da webcam do computador.

Outrossim, existe a ferramenta de desenho do PowerPoint, onde é possível escrever textos, sublinhar, grifar e apagar, desta forma a tela do computador tornase uma lousa digital e interativa. Após a gravação da aula há a possibilidade de fazer pequenas edições no próprio site Loom como cortes, acelerações e pequenas customizações, download para o computador, ou compartilhá-lo através de um link, deixando, assim, a aula mais interativa e lúdica. Nas Figuras 2 e 3 visualiza-se o desempenho de cada um deles (Animaker e PowerPoint em conjunto com o Loom) na criação de vídeos animados.

Figura 2 - Animaker

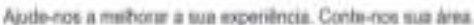

00

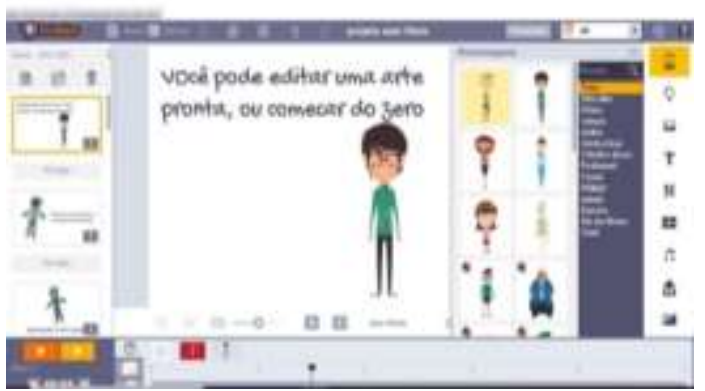

Fonte: captura de tela da ferramenta (2020).

${ }^{3}$ Disponível em: https://www.loom.com. Acesso em: 21 maio. 2020. 
Figura 3 - PowerPoint e Loom

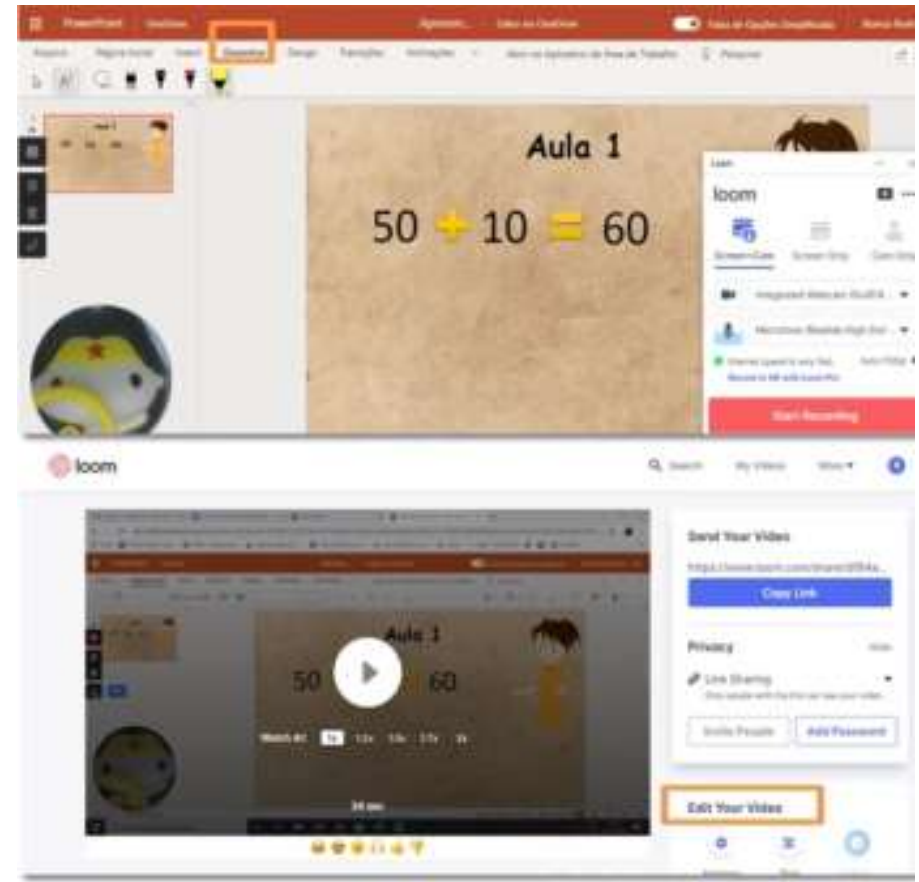

Fonte: captura de tela da ferramenta (2020).

Para as videoaulas gravadas, a edição do vídeo é uma etapa fundamental. Apesar de existir uma variedade de editores de vídeo, no caso específico de editores para smartphones, o InShoot $^{4}$ (Figura 4) é uma opção simples com diferentes funcionalidades como: corte, efeitos de luz, adição de som (do próprio aplicativo ou do seu aparelho), narração, filtros stickers animados, entre outras.

Figura 4 - Edição

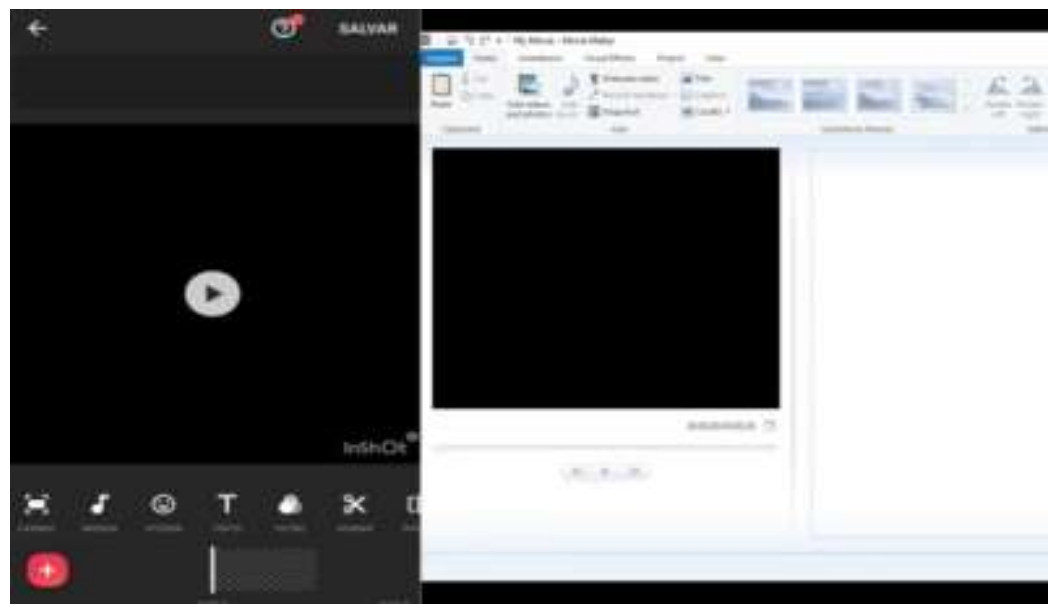

Fonte: captura de tela elaborada pelas autoras (2020).

\footnotetext{
${ }^{4}$ Disponível nas principais lojas de aplicativos.
} 
Para edição de vídeos em computadores e microcomputadores o Windows MovieMaker é uma boa opção e, dependendo do sistema operacional utilizado, este software pode já estar instalado no próprio computador. O Windows MovieMaker é uma ferramenta de edição de vídeo bem intuitiva, fazendo com que o tempo de edição diminua. É possível adicionar textos, transições, músicas, narrações, mas em comparação com o InShoot, possui menos funções a disposição do usuário.

\subsubsection{Videoconferências}

As ferramentas de videoconferências têm se constituído em dispositivos importantes nesse período de pandemia. Isso se justifica pelo fato de que elas contribuem sobremaneira para que as pessoas possam reunir-se e interagir em reuniões e aulas a distância, por exemplo. Nessa conjuntura, apresentamos o Google MeetGuide, ${ }^{5}$ o Zoom Cloud Meetings, ${ }^{6}$ o Teamlink $^{7}$ e o Skype $^{8}$ (Figura 5) como possibilidades potentes para uso no contexto educacional pandêmico.

Figura 5 - Mosaico das plataformas de videoconferência
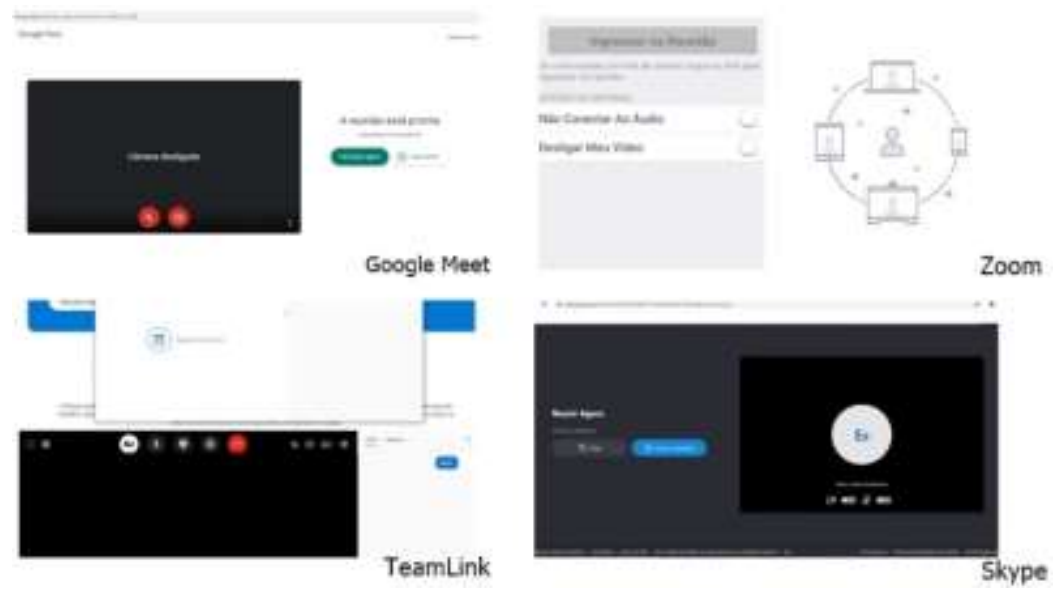

Fonte: captura de tela da ferramenta (2020).

O Google MeetGuide é um serviço gratuito de videoconferências que tem a capacidade para até 250 pessoas de forma simultânea, permitindo, assim, a

\footnotetext{
${ }^{5}$ Disponível em: https://www.meet.google.com. Acesso em: 22 jul. 2020.

${ }^{6}$ Disponível em: https://www.zoom.us/pt-pt/freesignup.html. Acesso em: 22 jul. 2020.

7 Disponível em: https://www.teamlink.co. Acesso em: 22 jul. 2020.

8 Disponível em: https://www.skype.com. Acesso em: 22 jul. 2020.
} 
interação de diversas pessoas, além do compartilhamento de materiais via chat, disponibilizados na própria plataforma. Apesar de ter capacidade para 250 pessoas, permite apenas que 16 pessoas sejam apresentadas de forma simultânea no painel. O Zoom Cloud Meetings, por sua vez, é um aplicativo da startup americana Zoom Vídeo Communications, utilizado para realizar e/ou participar de reuniões em videoconferência, podendo ser acessado por dispositivos móveis com sistemas operacionais Android ou iOS, além de computadores. O aplicativo permite convidar os participantes por e-mail, SMS e redes sociais e compartilhar arquivos, textos e apresentações durante as chamadas. Com a pandemia do Novo Coronavírus, ocorreu aumento da popularidade do aplicativo, principalmente pela variedade de funções, em sua maioria gratuita.

O Teamlink representa uma terceira opção para videoconferência e suporta até trezentas pessoas conectadas simultaneamente. Esta ferramenta permite que qualquer pessoa trabalhe junto com equipes e parceiros de qualquer lugar do mundo e a qualquer momento. Por outro lado, o Skype - ferramenta que surgiu em 2003, e em 2011 passou a pertencer a Microsoft - possui diversas funções gratuitas, como chamadas com vídeo e voz para outro usuário Skype, compartilhamento de arquivos, como vídeos e documentos, compartilhamento de tela e chat. O Skype foi uma das primeiras ferramentas a utilizar o sistema de videoconferência e pode ser utilizado tanto no computador como no celular.

É notória a semelhança tanto na interface, quanto nas funções das ferramentas supracitadas, o que pode determinar a escolha entre as opções é a quantidade de pessoas que estarão na sala e o suporte utilizado para acesso. Entretanto, admite-se que o Google Meet é o que mais se destaca, pois permite um maior número de pessoas em uma sala, além do mais, pode ser acessado diretamente na página da web, dispensando o download. A versão mobile, por sua vez, ocupa menos espaço de armazenamento no aparelho e ainda tem recebido destaque no quesito segurança de seus usuários.

\subsection{REDES SOCIAIS 9}

\footnotetext{
9 Todas as redes sociais citadas nesse tópico encontram-se disponíveis nas principais lojas de aplicativos.
} 
$O$ avanço das tecnologias interferiu nas formas de comunicação, resultando em uma mudança de hábito na conhecida cultura digital. A utilização de redes sociais no ensino a distância ganhou espaço nos últimos anos. O aplicativo WhatsApp Messenger, lançado em 2009, tem sido empregado como espaço de fórum e chat, assim como semelhantes recursos do Moodle. Segundo Blauth, Dias e Schererb (2019, p. 5, grifo nosso) "o WhatsApp é um aplicativo de comunicação utilizado por muitas pessoas no cotidiano, e que para a EaD [desponta] como um recurso para realização de encontros síncronos e assíncronos como o chat e o fórum, por exemplo."

Com a pandemia, o WhatsApp foi incorporado por muitas instituições de ensino como ferramenta de auxílio no processo de ensino e aprendizagem pela facilidade e rapidez de interação/comunicação entre alunos e professores. Além disso, diferente de outros aplicativos, ele é bastante utilizado por pessoas de vários níveis sociais e culturais. Para Mattar (2014) é uma ferramenta de comunicação rápida e promissora a ser utilizada como uma plataforma de apoio à educação, visto que possibilita o envio de textos, imagens, sons, vídeos, a criação de grupos de usuários, além de permitir também videoconferência em grupo com até oito pessoas.

Além do WhatsApp, o Facebook, Instagram, Twitter, TikTok e YouTube também possibilitam a realização de encontros virtuais, contudo, o Facebook, Instagram, YouTube e o TikTok apresentam um diferencial, que é a criação de lives ao vivo com interação em tempo real. O TikTok, por sua vez, exige uma quantidade mínima de mil seguidores para a realização de lives. O YouTube também possui essa restrição, mas apenas para realização de lives por dispositivos móveis, caso o usuário realize a transmissão por um computador ou microcomputador não enfrentará essa restrição. Moran (2015) adverte que estas ferramentas são relevantes em relação à interação/comunicação, pois possibilitam uma linguagem mais familiar e maior espontaneidade entre os participantes. Assim, várias instituições de ensino, inclusive aquelas que não possuem AVA ou outra ferramenta própria, podem optar pelas redes sociais para enviar planos de aulas, vídeo aulas, lembretes de reuniões etc. 


\subsection{BLOG E CHAT}

Blog e Chat entram na categoria de ferramentas de aprendizagem colaborativa, pois promovem a "alimentação" de conteúdos existentes ou a construção colaborativa de novos conteúdos. O Blog em especial, permite comentários e compartilhamentos, além de tornar a personalização da interface ainda mais atraente, como hospedeiros para o conteúdo do Blog, existem algumas plataformas, como o $\mathrm{Wix}^{10} \mathrm{e}$ o Blogger ${ }^{11}$.

O Wix (Figura 6) propicia acesso a uma biblioteca de imagens sem direitos autorais, e o compartilhamento direto nas redes sociais. Já com o Blogger (Figura 7), que tem interface mais simples para manipulação, o seu diferencial está na lista de leitura, onde é possível acessar outros blogs hospedados em seu servidor que abordam temas relacionados aos universos dos leitores que vão desde a resenha de livros, dicas de leitura até ideias de presente, acessórios para leitores, melhor iluminação.

Figura 6 - Configurações do blog Wix

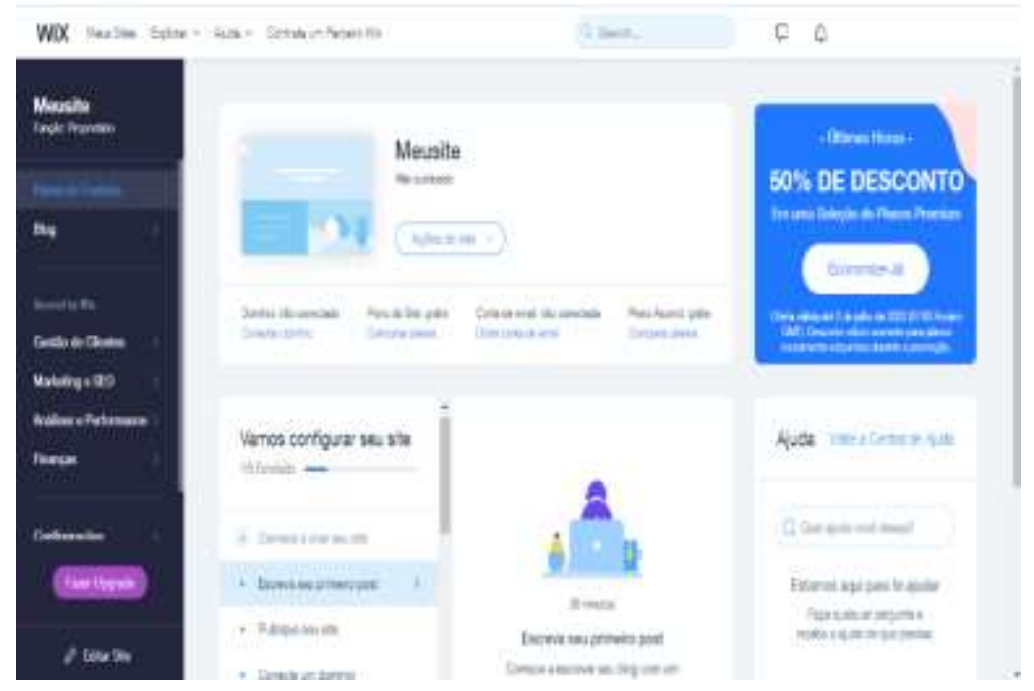

Fonte: captura de tela da ferramenta (2020).

\footnotetext{
10 Disponível em: https://pt.wix.com. Acesso em: 1 ago. 2020.

${ }^{11}$ Disponível em: https://www.blogger.com. Acesso em: 1 ago. 2020.
} 
Figura 7 - Blogger e a lista de leitura

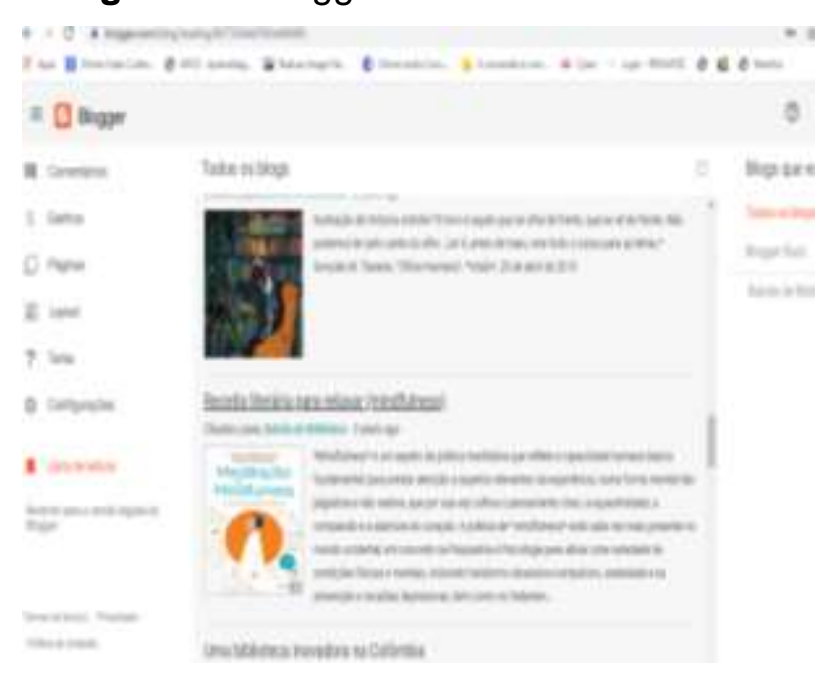

Fonte: captura de tela da ferramenta (2020).

O chat é outro exemplo de ferramenta de interação/comunicação. Nunes e demais autores (2020) definem o chat como uma das ferramentas de maior potencial para a interação mútua, devido a possibilidade de trocar mensagens de texto de maneira rápida e sendo possível anexar imagens. Para o uso dessa ferramenta, temos o BrasilChat ${ }^{12}$ (Figura 8), onde é possível criar uma sala, localizar amigos, enviar mídia. Para isso, é necessário fazer um breve cadastro e concordar com as políticas do chat, onde salientam que se deve manter uma conduta baseada nos padrões globais de etiqueta on-line.

Figura 8 - Página inicial BrasilChat

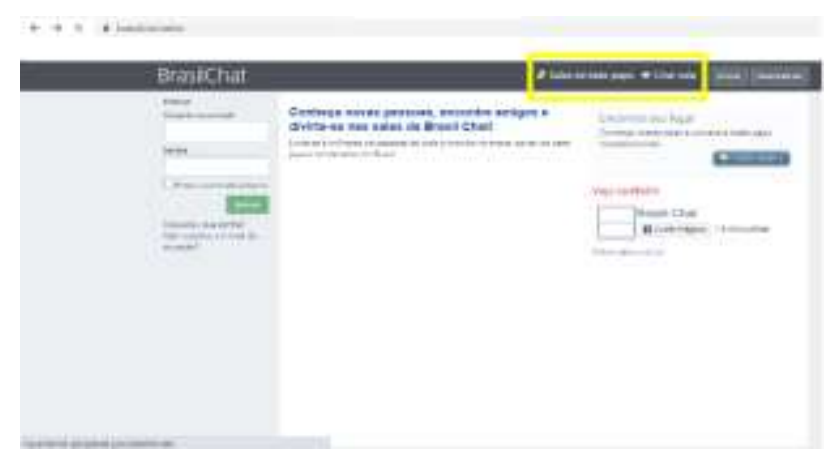

Fonte: captura de tela da ferramenta (2020).

12 Disponível em: https://www.brasilchat.net.br. Acesso em: 5 ago. 2020. 
Maia e Silva (2020) entendem que algumas práticas pedagógicas tendem a priorizar "conceitos unidirecionais de ensino", logo, independente da ferramenta, a tecnologia por si só não garante a interatividade. A reflexão dos autores é coerente tendo em vista as particularidades de cada indivíduo. Assim, para todas essas ferramentas aqui apresentadas, é sempre importante considerar os sujeitos da educação e a interação/diálogo que devem manter para lograr êxito no processo de ensino e aprendizagem.

\subsection{CUSTOMIZAÇÃO E ORGANIZAÇÃO}

Com o aumento do número de mensagens e mídias recebidas em nossos aparelhos, a customização e organização são tarefas primordiais. A customização parte do princípio de entender as suas demandas, criando postagens e conteúdos mais atrativos visualmente para que este seja consumido e, assim, os alunos fixem a atenção na mensagem ou conteúdo proposto. Já a organização auxilia na otimização do trabalho, diminuindo o tempo de busca por um material específico e aumenta a produtividade. Em relação à customização de materiais, temos uma ferramenta que se popularizou muito nos últimos anos, principalmente com a crescente usabilidade das redes sociais e kits para social mídia, que é o Canva ${ }^{13}$ (Figura 9):

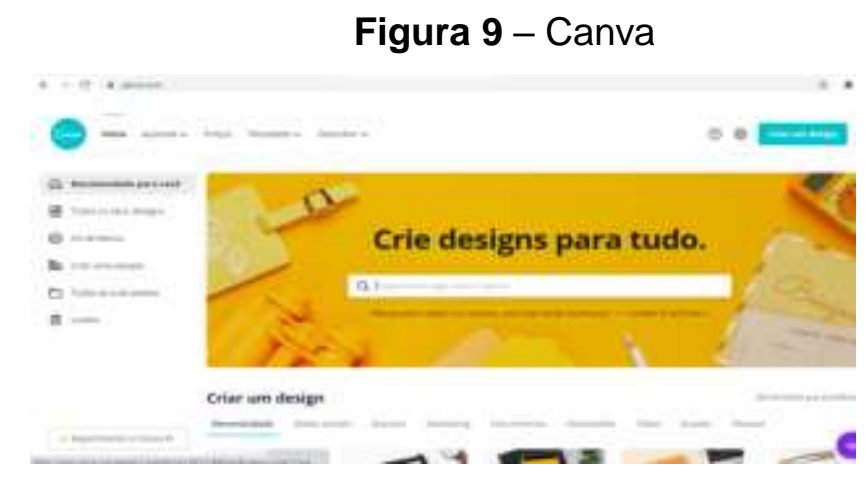

Fonte: captura de tela da ferramenta (2020).

\footnotetext{
${ }^{13}$ Disponível em: https://www.canva.com. Acesso em: 1 ago. 2020. Disponível também nas principais lojas de aplicativos.
} 
Por meio do Canva é possível editar e criar templates, gráficos, apostilas, cronogramas ou qualquer outro material visual. Com os presets fica fácil montar aulas dinâmicas que através do design integram um grande potencial para atrair a atenção dos alunos acerca do conteúdo do componente curricular. Para isso, também é necessário estar atento (a) ao uso de cores, de formas e à tipografia do texto facilitando a leitura e a compreensão do texto.

A organização dessas produções pode ser realizada no Pinterest, ${ }^{14}$ devido à facilidade em categorizar as pastas por série, assunto, matéria, entre outras categorias. Essa rede é também uma fonte de inspiração sobre diversos temas, fazendo com que as preferências baseadas nas interações realizadas recomendem novas pastas categorizadas, aumentando ainda mais a rede de pessoas que possuem afinidade sobre aquele nicho específico. Desta forma, é notório o seu poder de categorização e organização baseadas no percurso do usuário. No âmbito escolar, além das inspirações, é possível organizar e partilhar as ideias em outras plataformas, criando uma conexão.

As ferramentas oferecidas pelo Google são grandes aliadas para a organização dos conteúdos educacionais para implementação do ensino com auxílio das tecnologias de informação e comunicação. O Google Sala de Aula, ${ }^{15}$ por exemplo, permite a postagem de materiais, acompanhamento e avaliação de atividades, comentários e grupos de discussão. Outrossim, é possível organizar o conteúdo geral em pastas, em arquivos que vão direto para o Google Drive, deixando assim a organização personalizada. No caso da educação básica, o Google Sala de Aula permite o acompanhamento dos pais e/ou responsáveis e da direção da instituição de ensino.

\subsection{ALTERNATIVAS INCLUSIVAS}

O Podcast constitui-se como um forte aliado no contexto educacional, oferecendo arquivos de áudios gravados sobre diversos assuntos e apresenta como

\footnotetext{
14 Disponível em: https://br.pinterest.com. Acesso em: 1 ago. 2020. Disponível também nas principais lojas de aplicativos.

15 Disponível em: https://classroom.google.com. Acesso em: 17 ago. 2020. Disponível também nas principais lojas de aplicativos.
} 
principal característica a dinamicidade no compartilhamento de informações. Os arquivos de áudio são compartilhados na internet via plataformas "hospedeiras", a exemplo do SoundCloud, ${ }^{16}$ permitindo ao usuário criar playlists, fazer upload de seus arquivos e compartilhar. Desta forma, o Podcast pode ser empregado para inclusão de alunos cegos ou com baixa visão.

Figura 10 - Podcast em SoudCloud

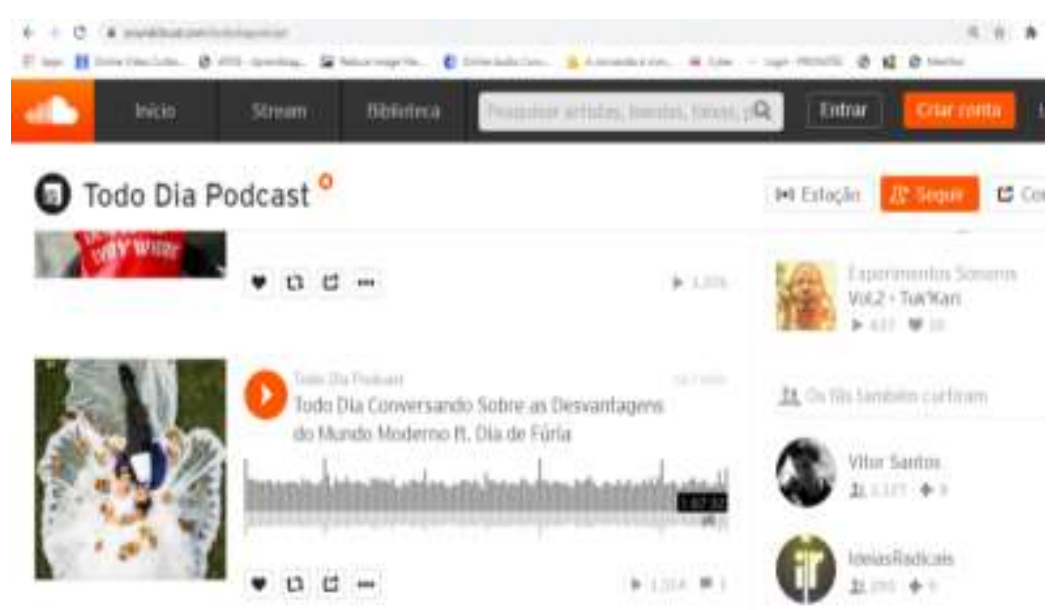

Fonte: captura de tela da ferramenta (2020).

Outra estratégia de inclusão no âmbito das ferramentas de apoio a educação é o VLibras. ${ }^{17}$ Brasil ([2014]) afirma ser um "conjunto de ferramentas computacionais de código aberto, que traduz conteúdos digitais (texto, áudio e vídeo) para Língua Brasileira de Sinais - LIBRAS, tornando computadores, celulares e plataformas web acessíveis para pessoas surdas." Ainda nesse contexto inclusivo, o HandTalk ${ }^{18}$ é um aplicativo que traduz o seu áudio em animação. Através do mascote Hugo é possível repetir e alterar a velocidade da animação. O HandTalk permite também a tradução de documentos digitais, páginas da web e fornece materiais para estudo da língua como videoaulas e e-books.

16 Disponível em: https://www.soundcloud.com. Acesso em: 17 ago. 2020.

17 Disponível em: https://www.softwarepublico.gov.br/social/suite-vlibras. Acesso em: 17 ago. 2020. Disponível também nas principais lojas de aplicativos.

18 Disponível em: https://www.handtalk.me. Acesso em: 15 ago. 2020. Disponível também nas principais lojas de aplicativos. 
Figura 11 - Assistentes de Libras

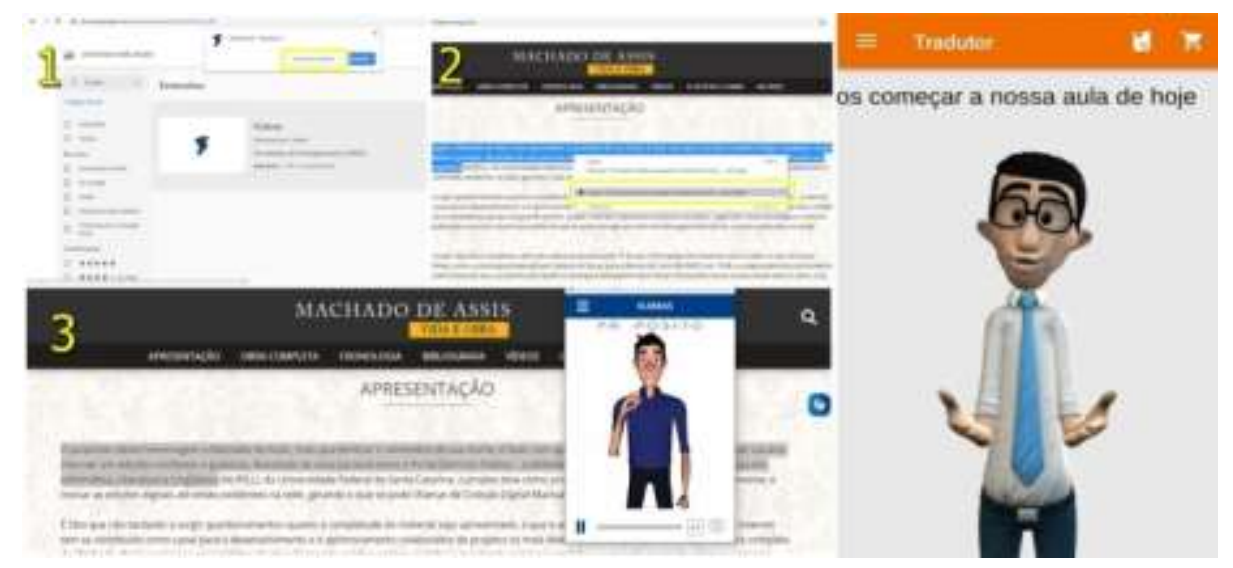

Fonte: captura de tela da ferramenta (2020).

Os assistentes possuem promessas e desempenho similares, porém com o uso é possível perceber que o VLibras tem maior funcionalidade na web. O Hand Talk nos smartphones é mais interativo por dispor de materiais de estudo complementar e aplicações do cotidiano com a função dicionário com sinais para execução em matérias como história, matemática, geografia etc.

Chega-se à percepção de que o uso de recursos das TIC no atual contexto educacional não presencial/remoto possibilita ao individuo acelerar o ritmo e a quantidade de informações acessadas que tende a contribuir no desenvolvimento educativo, favorecer o surgimento de novas linguagens e sintaxes, além de proporcionar a integração dos estudantes de forma livre e responsável no processo de ensino e aprendizagem.

\section{CONSIDERAÇÕES FINAIS}

É notório que as TIC no ambiente educacional constituem-se como ferramentas que corroboram na construção de novos conhecimentos entre os educadores e educandos, assim como as iniciativas antecessoras, como envio de cartas, radiodifusão e recursos televisionários. E com toda essa evolução, as TIC revelaram novas metodologias de ensino e aprendizagem através das telas, levando sempre em conta o papel do professor na mediação deste processo.

Dado o cenário atual de pandemia, reflexo do novo Coronavírus, o ensino remoto foi necessário, para o cumprimento das medidas sanitárias e a sala de aula 
agora não possui mais paredes, mas sim telas. Desta forma, foi preciso reinventarse com conteúdos mais interativos e novas formas de avaliação, controle, organização do processo ensino e aprendizagem. Neste contexto, o emprego de ferramentas tecnológicas pode promover essa interação no ensino e no desenvolvimento das competências dos estudantes, além de criar um novo significado, na interação entre professores, alunos e tutores. Essas ferramentas também estimulam a autonomia do aluno, tendo em vista que, em alguns casos, é possível assistir às aulas em quaisquer horários ou qualquer lugar. Em contrapartida, é exigido do aluno maior responsabilidade em lidar com as distrações e saber administrar bem o seu tempo de estudo.

Contudo, esclarece-se que a variedade de ferramentas que possibilitam a interação/comunicação no sistema de ensino não garante a equidade quanto ao acesso à educação num país como o Brasil, pois, o acesso à internet é desigual ao se comparar as classes sociais $A, B$ e $C$, como revelou a pesquisa da organização sem fins lucrativos Todos pela Educação, realizada em 2020. Neste estudo constatou-se que apenas $40 \%$ da classe social $C$ tem acesso à internet dificultando ainda mais o acesso à educação não presencial (TODOS PELA EDUCAÇÃO, 2020).

Ressalta-se, entretanto, que esse estudo não pretendeu ser conclusivo, tampouco explorar todas as características das ferramentas tecnológicas apresentadas, mas apresentá-las como possibilidades reais de uso nesse novo cenário da educação nacional e mundial.

\section{REFERÊNCIAS}

ALVES, João Roberto Moreira. A nova regulamentação da EAD no Brasil. In: SILVA, Marcos (org.). Educação online. 2. ed. São Paulo: Edições Loyola, 2006. p. 3.

ALVES, Lucineia. Educação a distância: conceitos e história no Brasil e no mundo.

Associação Brasileira de Educação a Distância, [s. I.], v. 10, p. 83-92, 2011. Disponível em:

http://www.abed.org.br/revistacientifica/Revista_PDF_Doc/2011/Artigo_07.pdf. Acesso em: 24 maio 2020.

BARROS, Josemir Almeida. Rádio e Educação: crianças ouvintes e leitoras de processos midiáticos. Associação de Leitura do Brasil, São Paulo, p. 1-13, [20--]. Disponível em:

http://alb.com.br/arquivomorto/edicoes_anteriores/anais17/txtcompletos/sem16/COL E_3107.pdf. Acesso em: 22 maio 2020. 
BLAUTH, Ivanete Fátima; DIAS, Nelson; SCHERER, Suely. WhatsApp como ambiente de interações na Educação à Distância; encontros síncronos e assíncronos. Holos Environment, Rio Claro, v. 6, p. 1-13, 2019. Disponível em: http://www2.ifrn.edu.br/ojs/index.php/HOLOS/article/view/6298. Acesso em: 6 jun. 2020.

BRASIL. Decreto n 9.057, de 25 de maio de 2017. Regulamenta o art. 80 da Lei no 9.394, de 20 de dezembro de 1996, que estabelece as diretrizes e bases da educação nacional. Diário Oficial da União, seção 1, Brasília, DF, ano 154, n. 100, p. 3-4, 26 maio 2017.

BRASIL. Lei $n^{\circ}$ 4.117, de 27 de agosto de 1962. Institui o Código Brasileiro de Telecomunicações. Diário Oficial da União, seção 1, Brasília, DF, p. 10413, 5 out. 1962.

BRASIL. Portaria $n^{\circ}$ 343, de 17 de março de 2020. Dispõe sobre a substituição das aulas presenciais por aulas em meios digitais enquanto durar a situação de pandemia do Novo Coronavírus - COVID-19. Diário Oficial da União, seção 1, Brasília, DF, ano 158, n. 53, p. 39, 18 mar. 2020a.

BRASIL. Portaria $n^{\circ} 345$, de 19 de março de 2020. Altera a Portaria MEC no 343, de 17 de março de 2020. Diário Oficial da União, seção 1, Brasília, DF, ano 158, n. 54d, p. 1, 19 mar. 2020b. Edição extra.

BRASIL. Portaria no 473, de 12 de maio de 2020. Dispõe sobre a prorrogação do prazo previsto no $\S 1^{\circ}$ do art. $1^{\circ}$ da Portaria $n^{\circ} 343$, de 17 de março de 2020. COVID-19. Diário Oficial da União, seção 1, Brasília, DF, ano 150, n. 90, p. 55, 13 maio 2020c. Disponível em: https://www.jusbrasil.com.br/diarios/296929006/dousecao-1-13-05-2020-pg-55?ref=feed. Acesso em: 7 jun. 2020.

BRASIL. Portaria n544, de 16 de junho de 2020. Dispõe sobre a substituição das aulas presenciais por aulas em meios digitais, enquanto durar a situação de pandemia do novo coronavírus - Covid-19, e revoga as Portarias MEC nํ3ㄴ de 17 de março de 2020, n³45, de 19 de março de 2020, e no 473, de 12 de maio de 2020. Diário Oficial da União, seção 1, Brasília, DF, ano 158, n. 114, p. 62, 17 jun. 2020d. Disponível em: http://www.in.gov.br/en/web/dou/-/portaria-n-544-de-16-dejunho-de-2020-

261924872\#: :text=Disp\%C3\%B5e\%20sobre\%20a\%20substitui\%C3\%A7\%C3\%A3o \%20das,12\%20de\%20maio\%20de\%202020.Acesso em: 14 jul. 2020.

CAMPELLO, Bernadete Santos; CENDÓN, Beatriz Valadares; KREMER, Jeannette Marguerite. Fontes de informação para profissionais. Belo Horizonte: EdUFMG, 2007.

COMO surgiu o EAD? EAD Conquiste seu diploma, [s. I.], 2020. Disponível em: https://www.ead.com.br/ead/como-surgiu-ensino-a-distancia.html. Acesso em: 23 maio 2020. 
FAN, Wu et al. A New Coronavirus Associated With Human Respiratory Disease in China. Nature, London, v. 579, n. 7798, p. 265-269, 2020. Disponível em: https://www.ncbi.nlm.nih.gov/pubmed/32015508. Acesso em: 24 maio 2020.

FREIRE, Flávio. A interação professor-aluno e suas implicações pedagógicas.

Revista de Ensino Educação e Ciências Humanas, Londrina, v. 1, n. 1, p. 115121, jun. 2000. Disponível em:

https://revista.pgsskroton.com/index.php/ensino/article/view/1196. Acesso em: 22 maio 2020.

FREIRE, Paulo. Educação e mudança. Rio de Janeiro: Paz e Terra, 1994.

FUNDAÇÃO ROBERTO MARINHO. Telecurso. Fundação Roberto Marinho, Rio de Janeiro, 2019. Disponível em: https://frm.org.br/acoes/telecurso/. Acesso em: 22 maio 2020.

LICERRO, Dener dos Santos; LUZ, Larissa Pavarinida. ArvoritoKids: Jogo Educacional Foco na Web sob a ótica de Interação Humana e Computador (IHC) a sua Importância. Revista e-F@tec, Garça, v. 9, n. 1, p. 1-31, 2019.

LINHA do tempo do Coronavírus no Brasil. Sanar Med, [s. l.],18 mar. 2020. Disponível em: https://www.sanarmed.com/linha-do-tempo-do-coronavirus-no-brasil. Acesso em: 24 maio 2020.

MAIA, Mirtes Dâmares Santos de Almeida; SILVA, Danilo Garcia da. Práticas Pedagógicas em Ambientes Virtuais de Aprendizagem: usos e abusos. Em Rede: Revista de Educação à distancia, Porto Alegre, v. 7, n.1, p. 81- 95, 2020.

MEIRINHOS, Manuel; OSÓRIO, António José. A colaboração em ambientes virtuais: aprender e formar no século XXI. Braga: Associação ArcaComum, 2014.

MOORE, Michael; KEARSLEY, Greg. Educação a distância: sistemas de aprendizagem on-line. 3. ed. São Paulo: Cengage Learning, 2013.

MATTAR, João. Design educacional: educação a distância na prática. São Paulo: Artesanato Educacional, 2014.

MORAN, José Manuel. Educação híbrida: um conceito-chave para a educação hoje. In: BACICH, Lilian; NETO, Adolfo Tanzi; TREVISANI, Fernando de Mello. Ensino híbrido: personalização e tecnologia na educação. Porto Alegre: Penso, 2015.p. 2752.

NUNES, Carlos Henrique Ferreira; BEZERRA, Aparecida Célia Rodrigues. Fundamentos da interação no contexto da educação a distância: uma análise dos processos interativos na Faculdade Estácio - polo Arapiraca. In: ENCONTRO INTERNACIONAL DE FORMAÇÃO DE PROFESSORES, 10.; FÓRUM PERMANENTE DE INOVAÇÃO EDUCACIONAL, 11., 2017, [Aracaju]. Anais [...]. [Aracaju]: Unit, 2017. p. 1-17. Disponível: em: 
https://eventos.set.edu.br/index.php/enfope/article/view/4996. Acesso em: 22 maio 2020.

NUNES, Enedina Betânia Leite de Lucena et al. A interação como indicador de qualidade na avaliação da educação a distância: um estudo de caso com docentes, tutores e discentes. Avaliação: Revista da Avaliação da Educação Superior, Campinas, v. 23, n. 3, p. 869-887, 2018.

NUNES, Paula Ávila. Guia Rápido para utilização do Edmod. [Curitiba]: Universidade Tecnológica Federal Do Paraná, 2018.

OLIVEIRA, Maria Orminda Santos et al. Análise do Fórum de Discussão como instrumento avaliativo no curso de Ciências Biológicas da UAB/UNIMONTES.

Multifaces: Revista de Ciência, Tecnologia e Educação, Montes Claros, v. 1, n. 1, p. 15-27, 2018.

SANTOS JUNIOR, Verissimo Barros; MONTEIRO, Jean Carlos da Silva. Educação e COVID-19: as tecnologias digitais mediando a aprendizagem em tempos de pandemia. Revista Encantar: Educação, Cultura e Sociedade, Bom Jesus da Lapa, v. 2 , p. $1-15,2020$.

SILVA, Camila Gonçalves; FIGUEIREDO, Vítor Fonseca. Ambiente virtual de aprendizagem: comunicação, interação e afetividade na EAD. Aprendizagem em EAD, Brasília, DF, v. 1, n. 1, p. 1-16, 2012. Disponível em: https://portalrevistas.ucb.br/index.php/raead/article/view/3254/2229 . Acesso em: 23 maio 2020.

TEMPO de concentração das pessoas na era digital é menor que o de um peixe dourado. O Globo, Rio de Janeiro, 14 maio 2015.

TODOS PELA EDUCAÇÃO (Movimento). Análise: Ensino à Distância na Educação Básica frente à pandemia da COVID-19. São Paulo: Todos pela Educação, 2020.

VALE, Helena Cristina Pimentel; MERCADO, Luis Paulo; PIMENTEL, Fernando Silvio Cavalcante. Condições de acesso a informação no contexto do polo de educação a distância da Universidade Aberta do Brasil. Revista Docência e Cibercultura, Rio de Janeiro, v. 2, n. 1, p. 39-68, 2018.Disponível em: https://www.epublicacoes.uerj.br/index.php/re-doc/article/view/30655/23584. Acesso em: 23 maio 2020.

VENDRUSCOLO, Maria Ivanice; BEHAR, Patrícia Alejandra. Investigando modelos pedagógicos para educação a distância: desafios e aspectos emergentes.

Educação, Porto Alegre, v. 39, n. 3, p. 302-311, 2016. 